\title{
CATECHOL 0-METHYLTRANSFERASE VAL158/MET AND HYPERTENSION: A META-ANALYSIS
}

\author{
Mohammed A. Merzah ${ }^{1,2}$ and Shewaye Natae ${ }^{1,3}$ \\ ${ }^{1}$ Department of Public Health and Epidemiology, Faculty of Medicine, University of Debrecen, Debrecen, \\ Hungary. \\ ${ }^{2}$ Department of Community Health, technical Institute of Karbala, Al-Furat Al-Awsat Technical University, \\ Karbala, Iraq. \\ ${ }^{3}$ Department of Public Health, College of Medicine and Health Science, Ambo University, Ethiopia.
}

Corresponding author: Mohammed A. Merzah

E-mail: mohammed.merzah@med.unideb.hu

\begin{abstract}
Hypertension is a preventable risk factor of cardiovascular diseases. It is considered as a major cause for the CVDmorbidity and mortality worldwide. Some risk factors and prevention strategies related to hypertension were studied intensively, however, with growing the burden of this disorder and genetic has become the dominant field of treating diseases, still specific genes involved in increasing blood pressure remain to be identified. This meta-analysis was conducted to assess the relationship of COMT Val158/Met variation to high systolic and diastolic blood pressure. PubMed and Web of Science (WOS) were intensively searched for genetic association on the link of COMT Val158/Met to hypertension. The search was done up to October $15^{\text {th }} 2020$ and updated on November $22^{\text {nd }} 2020$. Two investigators were independently extracting data and evaluating risk of bias using Cochrane risk of bias tool. Q-genie tool was used to assess the quality of all included articles. Met-dominant model (Met/Met + Val/Met vs Val/Val) showed a significant association to systolic and diastolic blood pressure with a pooled standardized mean difference of -0.215 and $95 \% \mathrm{Cl}[-$ 0.399 to -0.0300 ] and $-0.205,95 \% \mathrm{Cl}$ [-0.390 to -0.0197], respectively. Met allele was significantly related to high systolic and diastolic blood pressure. However, high-quality, case-control studies are lacking.
\end{abstract}

Keywords: COMT, rs4680, Val158/Met, catechol O-methyltransferase, hypertension, systolic blood pressure, diastolic blood pressure

\section{INTRODUCTION}

Cardiovascular diseases (CVDs) are listed among the first ten causes of death and result in high mortality rate worldwide ${ }^{1,2,3}$. Preventable risk factors of CVDs have been studies intensively, including hypertension, with the aim of eliminating the prevalence or improving the outcome of $\mathrm{CVDs}^{4}$. About half of CVD events were attributed to hypertension. Besides, it is recognized to be the major risk factor for CVD morbidity and mortality worldwide ${ }^{5}$. Alcohol consumption, obesity, high intake of salty-food or fatty-food and some genes were identified to be associated to blood pressure $(B P)^{6,7,8}$. It is a complex polygenic disease, about 120 single nucleotide polymorphism and more than twentyfive mutations were identified to be attributed to hypertension9. Despite a favourable modification of unhealthy lifestyle, effectiveness of using some antihypertensive drugs, and genetically determined of some risk factors, still specific genes involved in increasing $\mathrm{BP}$ remain to be identified.

Catechol 0-methyltransferase (COMT) is an enzyme that has two versions; a membrane-bound form (MB-COMT) which is mainly produced in the brain, and a soluble form (S-COMT) which is produced in the liver, kidney and blood ${ }^{10}$. COMT has an important role not only in degradation the catecholamine transmitters, but also breaking down the drugs used to treat hypertension ${ }^{11}$.

A single nucleotide polymorphism (SNP) located on the fourth exon, 158 codon of COMT-gene has found to be related to the activity of the gene ${ }^{10}$. Changing in amino acid Methionine (Met) instead of Valine ( $\mathrm{Val}$ ) has been shown to be related in decreasing the catecholamine-degradation activity; and thus leading to increase the availability of dopamine. The enzymatic activity of COMT- gene has found to be three to four-folds decrease among homozygous Met-carriers ${ }^{12}$.

Recently, COMT Val158Met was studied with regards to hypertension variations. Some studies show that Met-homogenous was associated with high systolic and diastolic blood pressure $13,14,15,16$; however, other show a reverse finding ${ }^{17}$. Such contradictions in reporting the association of COMT Val158/Met to hypertension encouraged us to conducting a meta-analysis of these studies.

\section{METHODS}

PubMed and Web of Science (WOS) were intensively searched for genetic association on the link of COMT Val158/Met to Hypertension. The search was done up to October $15^{\text {th }} 2020$ and 
updated on November 22 2020 using these keywords: 'COMT', 'rs4680', 'hypertension', 'blood pressure', 'systolic blood pressure', and 'diastolic blood pressure'. References of the selected studies were screened manually to find relevant studies were not indexed by PubMed or WOS. Five out of sixty-two articles were included in this meta study (Figure 1).

Criteria to include studies were set as: (1) rs4680 of COMT- gene should be genotyped for all participants; (2) Means and standard deviations (SD) of systolic (SBP) and diastolic blood pressure (DBP) should be reported separately by genotype; (3) study subjects should not be overlap between studies; if so, the study with highest sample size will be selected; (4) The distribution genotype should follow Hardy-Weinberg Equilibrium (HWE); (5) Blood pressure should be measured at least twice with reporting the mean of the two measurements. Studies were excluded when either reported pulse pressure or not reporting interquartile range (IQR) of the median of SBP and DBP. Data from each single study were extracted as they shown on table 1 .

All included articles were assessed for quality using Q-genie tool ${ }^{18}$, while Cochrane risk of bias tool was used to evaluate the risk of bias.

\section{Statistical Analysis}

To assess the relationship of Met-dominant model (Met/Met + Val/Met vs Val/Val) of COMT-gene (rs4680) to hypertension, a meta-analysis was used. Mean and standard deviation of SPB and DBP of each study was compared separately to Metdominant model using random effect model with $95 \% \mathrm{Cl}$. A $t$-test was used to examine the pooled mean difference, and would considered significant when $p<0.05$. Heterogeneity among studies was computed using Q-test, which follows a $\mathrm{X}^{2}$-distribution with $\mathrm{df}=\mathrm{n}-1$, where $\mathrm{n}$ is the number of the included studies. To specify the percent of differences across studies due to heterogeneity, $I^{2}$ metric was computed $\left(I^{2}=\mathrm{Q}\right.$ $\mathrm{df} / \mathrm{Q}){ }^{19}$. The range of $P^{2}$ is from 0 to 100 , the highest the $I^{2}$-value means high heterogeneity ${ }^{20}$. A random-effects model was used in this metaanalysis as the heterogeneity existed based on the consideration that a variation is extant withinstudies and between-studies ${ }^{21}$. A sensitivity analysis was performed by removing one study at a time to assess whether the significant of pooled mean difference was contributed to a single study. All meta-analyses were performed by MedCalc (v. 19.5.1).

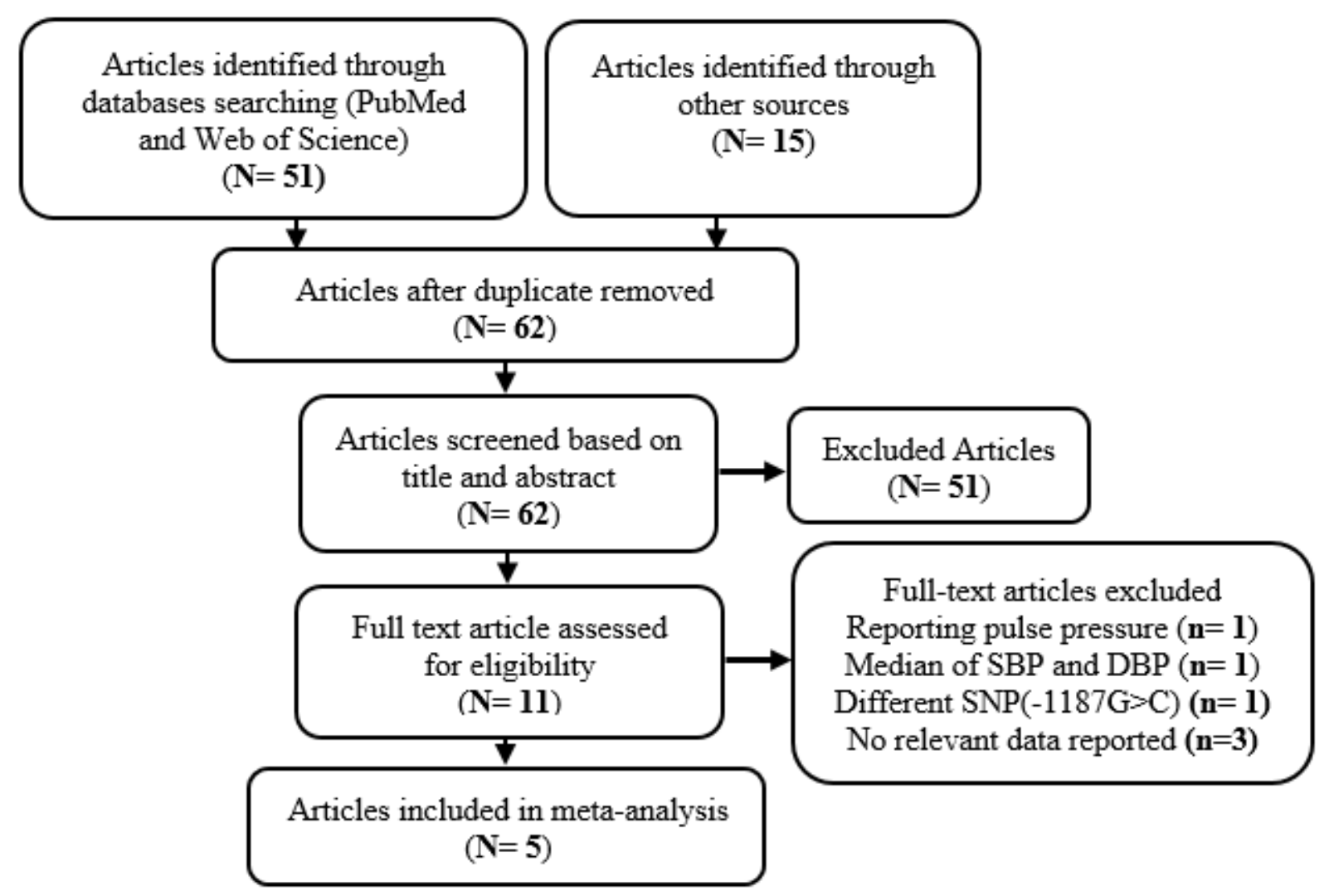

Figure 1: PRISMA flow chart illustrating studies selection process 
Malaysian Journal of Public Health Medicine 2021, Vol. 21 (2): 162-167

Table1: Characteristics of studies included in meta-analysis $(\mathrm{N}=5)$

\begin{tabular}{|c|c|c|c|c|c|c|}
\hline Study & $\begin{array}{c}\text { Count } \\
\text { ry }\end{array}$ & $\begin{array}{c}\text { Sample } \\
\text { size }\end{array}$ & $\begin{array}{c}\text { Mean } \\
\text { age }\end{array}$ & $\begin{array}{c}\text { Mean SBP } \\
(\mathrm{mmHg})\end{array}$ & $\begin{array}{c}\text { Mean DBP } \\
(\mathrm{mmHg})\end{array}$ & $\begin{array}{l}\text { Allele Freq. } \\
\text { Met/Val }\end{array}$ \\
\hline Yeh, $2010^{13}$ & $\begin{array}{c}\text { Taiwa } \\
\mathrm{n}\end{array}$ & 558 & $\begin{array}{c}16.3 \pm 0 \\
5\end{array}$ & $113.9 \pm 12.1$ & $71.8 \pm 8.3$ & $0.30 / 0.70$ \\
\hline $\mathrm{Ge}, 2015^{17}$ & China & 3079 & $\begin{array}{c}55.5 \pm 23 \\
.6\end{array}$ & $136.6 \pm 25.4$ & $83.8 \pm 11.5$ & $0.25 / 0.75$ \\
\hline Htun, $2011^{14}$ & Japan & 735 & $\begin{array}{c}47.0 \pm 8 \\
9\end{array}$ & $129.9 \pm 17.5$ & $79.8 \pm 11.8$ & $0.31 / 0.69$ \\
\hline $\begin{array}{l}\text { Annerbrink, } \\
2008^{15}\end{array}$ & $\begin{array}{c}\text { Swede } \\
n\end{array}$ & 204 & - & $127.1 \pm 15.8$ & $82.6 \pm 10.0$ & $0.54 / 0.46$ \\
\hline Stewart, $2009^{16}$ & USA & 839 & $\begin{array}{c}44.2 \pm 10 \\
.5\end{array}$ & $134.6 \pm 18.1$ & $83.6 \pm 11.2$ & $0.46 / 0.54$ \\
\hline
\end{tabular}

\section{RESULTS}

A total of 5415 subjects from five studies were included in this meta-analysis with a study sample size 204 to 3079. Accumulatively, 4372 subjects were Asian-ancestry from three different countries, 204 were European- ancestry, while the others were American-ancestry.

In regards to the association of COMT (Val158/Met) with systolic blood pressure, the analysis of the Met-dominant model (Met/Met + $\mathrm{Val} / \mathrm{Met}$ vs $\mathrm{Val} / \mathrm{Val}$ ) showed a significant association to SBP with a pooled standardized mean difference of -0.215 and $95 \% \mathrm{Cl}[-0.399$ to 0.0300] (Figure 2). Likewise, a significant pooled standardized mean difference was found between the Met-dominant model (Met/Met + Val/Met vs $\mathrm{Val} / \mathrm{Val}$ ) of COMT-gene and diastolic blood pressure, SDM=-0.205, $95 \% \mathrm{Cl}[-0.390$ to -0.0197$]$ (Figure 3).

\begin{tabular}{|c|c|c|c|c|c|c|}
\hline \multirow[b]{2}{*}{ Study } & \multicolumn{2}{|c|}{ COMT genotype } & \multirow[b]{2}{*}{ Total } & \multirow[b]{2}{*}{ SMD, random $[95 \% \mathrm{CI}]$} & \multirow[b]{2}{*}{ Weight } & \multirow[b]{2}{*}{$\begin{array}{c}\text { Standardized mean difference, } \\
\text { random, } 95 \% \mathrm{CI}\end{array}$} \\
\hline & GG & $\begin{array}{c}\mathrm{AA}^{+} \\
\text {GA }\end{array}$ & & & & \\
\hline Yeh, 2010 & 279 & 279 & 558 & $-0.261[-0.428$ to -0.0941$]$ & $20.46 \%$ & \\
\hline $\mathrm{Ge}, 2015$ & 1785 & 1294 & 3079 & $0.0291[-0.0425$ to 0.101$\rceil$ & $23.68 \%$ & . \\
\hline Htun 2011 & 357 & 378 & 735 & $-0.344[-0.489$ to -0.198$]$ & $21.3 \%$ & . \\
\hline Annerbrink, 2008 & 42 & 162 & 204 & $-0.483[-0.827$ to -0.140$]$ & $13.34 \%$ & 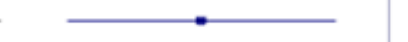 \\
\hline Stewart, 2009 & 253 & 586 & 839 & $-0.143[-0.291$ to 0.00448$]$ & $21.22 \%$ & \\
\hline Total $(95 \% \mathrm{CI})$ & & & 5415 & $-0.215[-0.399$ to -0.0300$]$ & $100 \%$ & \\
\hline Total events & 2716 & 2699 & & & & \\
\hline \multicolumn{6}{|c|}{$\begin{array}{l}\text { Heterogeneity: } \chi^{2}=31.945, \mathrm{df}=4,(\mathrm{p}<0.0001), I=87.48 \% \\
\text { Test for overall effect: } t=-2.279(\mathrm{p}=0.023)\end{array}$} & 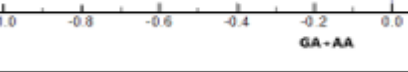 \\
\hline
\end{tabular}

Figure 2: Standardized mean difference of systolic blood pressure with rs4680 (COMT Val158/Met). G, Val; A, Met.

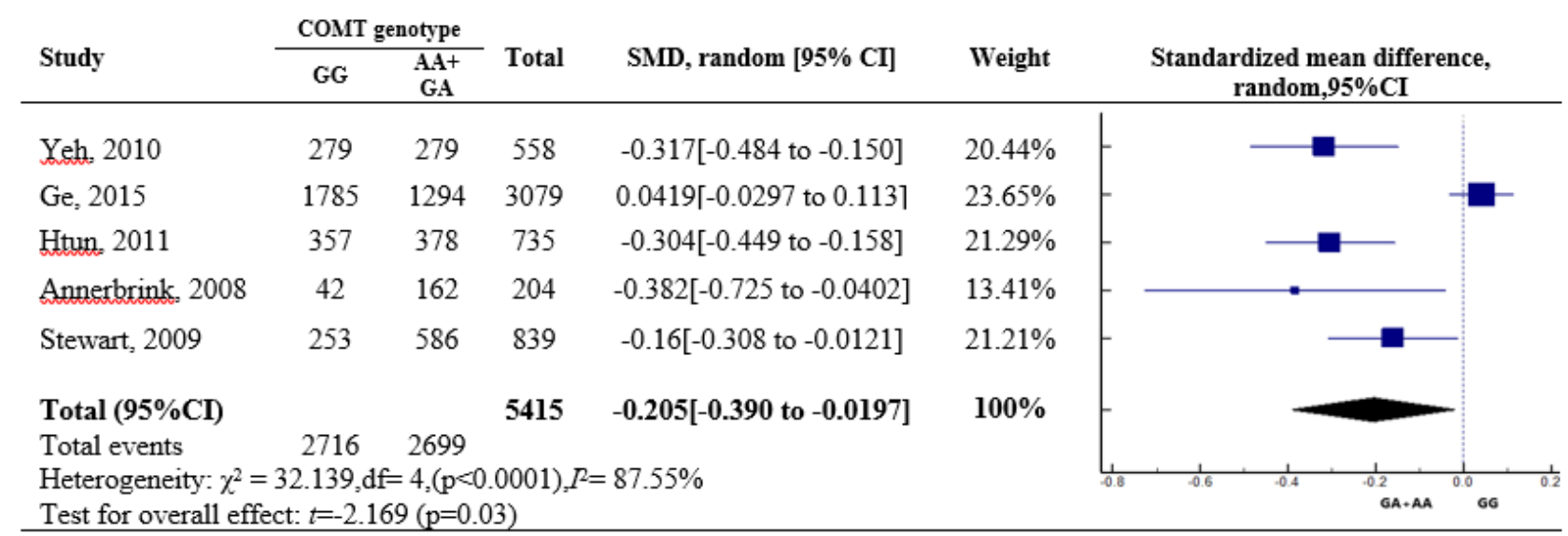

Figure 3: Standardized mean difference of diastolic blood pressure with rs4680 (COMT Val158/Met). G, Val; A, Met. 


\section{DISCUSSION}

This analysis was conducted to assess the relationship of Val/Met allele variants on hypertension/high blood pressure. The standardized mean difference of SBP and DBP were assessed using Met-dominant model of COMT- rs4680. However, Val-dominant model was not applied due to the unreported SBP and DBP values for $\mathrm{Val}$-homogenous carrier in one of the included studies. A random effect model was used to analyse data since there were high heterogeneity between-included studies. A significant pooled standardized mean difference was found between Met-dominant model of COMT val158/Met and hypertension (SBP and DBP).

The prevalence of high blood pressure among European population is $60 \%$ as compared to United States and Canada ${ }^{22}$. It is contributed to $25 \%$ of heart attack in European countries ${ }^{22}$. However, the prevalence of hypertension among East-Asian population were range $7-38 \%$ in women and $5-47 \%$ in men ${ }^{23}$. This shows a variation in the prevalence of hypertension among different ethnic groups of the population. Likewise, the allelic frequencies were wide-ranging among included studies as they conducted on different ethnic groups, and that might be contributed to the high heterogeneity of this analysis. To emphasize, Asian-descent were having approximately an analogous allele frequency of Val158/Met (Met $=0.25-0.31 / \mathrm{Val}=$ $0.69-0.75)$ with high frequency of $\mathrm{Val}$ allele (Table 1); while, Met allele was higher among European-descent $(0.54 \%)$. From all included studies, the frequency of the minor allele (Met/A) is low among Asian and American populations compared to European-descent population, the same reported by others ${ }^{24,25,26,27,28}$. High heterogeneity might be attributed to not only the variation of allelic frequencies, but also to the low number of included reports, sample size of each included studies, and diversity in age of subjects between- and within-studies.

Only one study shows that Val-homozygous genotype is linked to the high S/DBP, though it was not significant in this analysis. In contrast, Met-dominant model was related significantly to high SBP in three studies (Figure 2), and to high DBP in four studies (Figure 3). This analysis revealed significantly that Met-allele is associated with elevating S/DBP. This finding is in a harmony with the fact that low COMT activity is linked to Met-allele; as the former leads to increase the concentrations of two important hormones that are control BP (estrogen and dopamine) ${ }^{13,29,30}$. It is worthy knowing that each of the two hormones regulate BP in multifaceted and different pathways; for instance, dopamine plays an important role in regulating $\mathrm{BP}$ through regulating blood flow, heart rate, sodium excretion, glomerular filtration rate, and secretion of catecholamine $^{31}$. Indeed, these pathways regulate BP in different ways, some elevate and others lower BP. Therefore, further studies on understanding the collaborative effects of estrogen and dopamine on BP might pave the way to a better understanding on the effect of COMT genotype.

The inconsistent findings of the included studies might be credited to the fact that Ge et al., study has a wide range of age $(55.5 \pm 23.6)$, environmental unmatched subjects (Bama and Pinggue areas with $200 \mathrm{~km}$ distance, China), and both genders were included; though with highest sample size of the included studies. This study was the only one that linked Val allele to high S/DBP. In contrast, other four studies were revealed an opposite finding as Met-allele was found to be related to the high S/DBP. Two of them were in accord to $\mathrm{Ge}$ et al., as all carried on East-Asiandescent subjects; however, with a narrow range of age and single gender. One study was carried on Japanese-men only with middle age $(47.0 \pm 8.9)^{14}$; while the other study was conducted on adult-young-Taiwan-females only with mean age of 16.3 and standard deviation of $0.5^{13}$. Interestingly, a harmony finding to that of Htun et al., and Yeh et al., was publicised among Swedish middle-age men (51 year $)^{15}$. Likewise, a significant effect of Met-allele on BP was found among middle age $(44.2 \pm 10.5)$ of both genders of different ethnic group of American subjects ${ }^{16}$. Unfortunately, the latter study ${ }^{16}$ has not reported SBP and DBP by ethnic group as $95 \%$ of the included subjects were African-American, Hispanic, and non-Hispanic- descent; if so, it would be valuable to analyse data by ethnicity. In sum, variety of the age-group might be the main confounder that leads to unlike findings of the four included studies to the study of $\mathrm{Ge}$ and $\mathrm{co}$ workers.

\section{CONCLUSION}

Altogether, this analysis revealed a dependent link of Met-allele to high S/DBP. Though and due to the low number of published reports on the effect of COMT-rs4680 genotype on BP, further studies need to be conducted to attain a better understanding on the link of COMT genotype to hypertension. Besides, other SNPs of COMT gene should not be neglected (ex: rs4633, rs4818, and rs6269) when assessing its link to any phenotype; in addition, some behaviours would be valuable to be considered as well. For instance, energy intake ${ }^{14}$ or alcohol consumption ${ }^{16}$ might be allied to the effect of Met- allele of COMT-gene on BP.

\section{Conflict of interest}

The authors declare no potential conflict of interest.

\section{Funding}

This work has been funded EFOP-3.6.1-16-201600022 Debrecen Venture Catapult Program Data Intensive and Open Science School, Faculty of Medicine, University of Debrecen. 


\section{REFERENCES}

1. Mc Namara K, Alzubaidi H, Jackson JK. Cardiovascular disease as a leading cause of death: how are pharmacists getting involved?. Integr Pharm Res Pract. 2019;8:1-11. Published 2019 Feb 4. doi:10.2147/IPRP.S133088

2. Tsushima H, Yamamoto $\mathrm{H}$, Kitagawa $\mathrm{T}$, et al. Association of Epicardial and Abdominal Visceral Adipose Tissue With Coronary Atherosclerosis in Patients With a Coronary Artery Calcium Score of Zero. Circ J. 2015;79(May):1-2. doi:10.1253/circj.CJ-14-1169

3. Maarman GJ, Chakafana G, Sliwa K. World Heart Day: a World Heart Federation communiqué on the future of basic sciences and translational medicine in global cardiovascular research. Am J Physiol Lung Cell Mol Physiol. 2020 Sep 1;319(3):L545-L546. doi: 10.1152/ajplung.00339.2020. Epub 2020 Jul 29. PMID: 32726129.

4. Flora GD, Nayak MK. A Brief Review of Cardiovascular Diseases, Associated Risk Factors and Current Treatment Regimes. Curr Pharm Des. 2019;25(38):4063-4084. doi:10.2174/138161282566619092516382 7

5. Lawes CMM, Hoorn S Vander, Rodgers A, Society I. Global burden of bloodpressure-related disease , 2001. Lancet. 2001:1513-1518.

6. Ondimu DO, Kikuvi GM, Otieno WN. Risk factors for hypertension among young adults (18-35) years attending in Tenwek Mission Hospital, Bomet County, Kenya in 2018. Pan Afr Med J. 2019;33(210). doi:10.11604/pamj.2019.33.210.18407

7. Shen $Y$, Chang C, Zhang J, Jiang $Y, N i B$, Wang $Y$. Prevalence and risk factors associated with hypertension and prehypertension in a working population at high altitude in China: a crosssectional study. Environ Health Prev Med. 2017;22(19):1-8. doi:10.1186/s12199017-0634-7

8. Samadian F, Dalili N, Jamalian A. Lifestyle Modifications to Prevent and Control Hypertension Review. Iran J Kidney Dis I. 2016;10(5):237-263.

9. Freis ED, Arias LA, Armstrong ML, Blount AW. Effects of Treatment on Morbidity in Hypertension. JAMA. 1967;202(11).

10. Salminen M, Jalanko ANU, Savolainen R. Cloning and Characterization of Human
Placental Catechol-0-methyltransferase. DNA Cell Biol. 1991;10(3):181-189.

11. Qayyum A, Zai CC, Hirata Y, et al. The Role of the Catechol-o-methyltransferase ( COMT ) Gene Val158Met in Aggressive Behavior, A Review of Genetic Studies. Curr Neuropharmacol. 2015;13:802-814.

12. Kestler LJ, Mazzanti C, Ph D, et al. A Functional Polymorphism in the COMT Gene and Performance on a Test of Prefrontal Cognition. Am J Psychiatry. 2002;159(April):652-654

13. Yeh T-K, Yeh T-C, Weng C-F, et al. Association of polymorphisms in genes involved in the dopaminergic pathway with blood pressure and uric acid levels in Chinese females. J Neural Transm. 2010;117:1371-1376. doi:10.1007/s00702010-0492-6

14. Htun NC, Miyaki K, Song $\mathrm{Y}$, Ikeda S, Shimbo T, Muramatsu M. Association of the Catechol- 0 -Methyl Transferase Gene Val158Met Polymorphism With Blood Pressure and Prevalence of Hypertension : Interaction With Dietary Energy Intake. Am J Hypertens. 2009;24(9):1022-1026. doi:10.1038/ajh.2011.93

15. Annerbrink $\mathrm{K}$, Westberg $\mathrm{L}$, Nilsson $\mathrm{S}$, Rosmond R, Holm G, Eriksson E. Catechol O -methyltransferase val158-met polymorphism is associated with abdominal obesity and blood pressure in men. Metab Clin Exp. 2008;57:708-711. doi:10.1016/j.metabol.2008.01.012

16. Stewart SH, Oroszi G, Randall PK, Anton RF. COMT Genotype Influences the Effect of Alcohol on Blood Pressure: Results From the COMBINE Study. Am J Hypertens. 2009;22(1):87-91. doi:10.1038/ajh.2008.321

17. Ge L, Wu HY, Pan SL, et al. COMT Val158Met polymorphism is associated with blood pressure and lipid levels in general families of Bama longevous area in China. Int $J$ Clin Exp Pathol. 2015;8(11):15055-15064.

18. Sohani ZN, Meyre D, de Souza RJ, et al. Assessing the quality of published genetic association studies in meta-analyses: The quality of genetic studies (Q-Genie) tool. BMC Genet. 2015;16(1):1-8. doi:10.1186/s12863-015-0211-2

19. Lau J, loannidis JPA, Schmid $\mathrm{CH}$. Quantitative Synthesis in Systematic Reviews. Ann Intern. 1997;127(9):820826. 
20. Zintzaras E, Hadjigeorgiou $\mathbb{E}$ EM. Association of paraoxonase 1 gene polymorphisms with risk of Parkinson's disease: a meta-analysis. J Hum Genet. 2004;49:474-481. doi:10.1007/s10038004-0176-x

21. Dersimonian R, Laird N. Meta-Analysis in Clinical Trials *. 1986;188:177-188.

22. WHO. High blood pressure - country experiences and effective interventions utilized across the European Region. WHO Reg Off Eur. 2013.

23. Chiang C, Chen C. Hypertension in the Asia-Pacific region. J Hum Hypertens. 2008;22:441-443.

doi: $10.1038 /$ jhh. 2008.17

24. Witte AV, Jansen S, Schirmacher A, Young P, Flöel A. COMT Val 158 Met polymorphism modulates cognitive effects of dietary intervention. Neurosci Aging. $\quad 2010 ; 2$ (November):1-7. doi:10.3389/fnagi.2010.00146

25. Ittiwut1 R, Listman JB, Ittiwut C, et al. Association between polymorphisms in catechol-0- methyltransferase (COMT) and cocaine-induced paranoia in European-American and African-American populations. Am J Med Genet B Neuropsychiatr Genet. 2011;6. doi:10.1002/ajmg.b.31205.Association

26. Yoshida T, Kato K, Yokoi K, et al. Association of genetic variants with chronic kidney disease in individuals with different lipid profiles. Int J Mol Med. 2009;24:233-246. doi:10.3892/ijmm

27. Wang Q, Li H, Beijing T, Yuan P, Li J. Soy isoflavones, CYP1A1, CYP1B1, and COMT polymorphisms, and breast cancer: A case-control study in southwestern China. DNA Cell Biol. 2010;(March 2011). doi:10.1089/dna.2010.1195

28. Zhang Y, Chen M, Chen J, Wu Z. Metabolic syndrome in patients taking clozapine: prevalence and influence of catechol-0methyltransferase genotype.

Psychopharmacology (Berl). 2014;231:2211-2218. doi:10.1007/s00213013-3410-4

29. Antentor Othrell Hinton Jr. YH, Xia Y, Xu $P$, et al. Estrogen Receptor- $a$ in the Medial Amygdala Prevents Stressinduced Elevations in Blood Pressure in

Females.pdf. Hypertension.
30. Xue B, Zhang Z, Beltz TG, Guo F, Hay M, Johnson AK. Estrogen regulation of the brain renin-angiotensin system in protection against angiotensin II-induced sensitization of hypertension. $A m \mathrm{~J}$ Physiol Circ Physiol. 2014;307(2):191-198. doi:10.1152/ajpheart.01012.2013

31. Contreras F, Fouillioux C, Simonovis N, Herna $R$, Velasco M. Dopamine, hypertension and obesity. $J$ Hum Hypertens. 2002;16(S1):S13-S17. doi: $10.1038 / \mathrm{sj} / \mathrm{jhh} / 1001334$ 